\title{
GABA-A receptor differences in schizophrenia: a positron emission tomography study using $\left[{ }^{11} \mathrm{C}\right]$ Ro154513
}

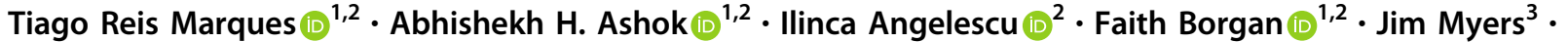 \\ Anne Lingford-Hughes ${ }^{4} \cdot$ David J. Nutt $\mathbb{D}^{4} \cdot$ Mattia Veronese $\mathbb{D}^{5} \cdot$ Federico E. Turkheimer $^{5} \cdot$ Oliver D. Howes ${ }^{1,2}$
}

Received: 30 September 2019 / Revised: 17 February 2020 / Accepted: 4 March 2020 / Published online: 15 April 2020

(c) The Author(s) 2020. This article is published with open access

\begin{abstract}
A loss of GABA signaling is a prevailing hypothesis for the pathogenesis of schizophrenia. Preclinical studies indicate that blockade of the $\alpha 5$ subtype of the GABA receptor $\left(\alpha 5-G_{A B A} R s\right)$ leads to behavioral phenotypes associated with schizophrenia, and postmortem evidence indicates lower hippocampal $\alpha 5-G_{A B A} R$ s protein and mRNA levels in schizophrenia. However, it is unclear if $\alpha 5-\mathrm{GABA}_{\mathrm{A}} \mathrm{Rs}$ are altered in vivo or related to symptoms. We investigated $\alpha 5-$ $\mathrm{GABA}_{\mathrm{A}} \mathrm{Rs}$ availability in antipsychotic-free schizophrenia patients and antipsychotic-medicated schizophrenia patients using $\left[{ }^{11} \mathrm{C}\right]$ Ro15-4513 PET imaging in a cross-sectional, case-control study design. Thirty-one schizophrenia patients $(n=$ 10 antipsychotic free) and twenty-nine matched healthy controls underwent a $\left[{ }^{11} \mathrm{C}\right]$ Ro15-4513 PET scan and MRI. The $\alpha 5$ subtype GABA-A receptor availability was indexed using $\left[{ }^{11} \mathrm{C}\right]$ Ro15-4513 PET imaging. Dynamic PET data were analyzed using the two-tissue compartment model with an arterial plasma input function and total volume of distribution $\left(V_{\mathrm{T}}\right)$ as the outcome measure. Symptom severity was assessed using the PANSS scale. There was significantly lower [11C] Ro15-4513 $V_{\mathrm{T}}$ in the hippocampus of antipsychotic-free patients, but not in medicated patients $(p=0.64)$, relative to healthy controls $(p<0.05$; effect size $=1.4)$. There was also a significant positive correlation between $\left[{ }^{11} \mathrm{C}\right] \mathrm{Ro} 15-4513 V_{\mathrm{T}}$ and total PANSS score in antipsychotic-free patients $(r=0.72 ; p=0.044)$. The results suggest that antipsychotic-free patients with schizophrenia have lower $\alpha 5$-GABAARs levels in the hippocampus, consistent with the hypothesis that GABA hypofunction underlies the pathophysiology of the disorder.
\end{abstract}

Supplementary information The online version of this article (https:// doi.org/10.1038/s41380-020-0711-y) contains supplementary material, which is available to authorized users.

Tiago Reis Marques

t.dos-reis-marques@1ms.mrc.ac.uk

1 Psychiatric Imaging Group, MRC London Institute of Medical Sciences (LMS), Imperial College London, London, UK

2 Department of Psychosis Studies, Institute of Psychiatry, Psychology and Neuroscience, King's College London, London, UK

3 Faculty of Medicine, Imperial College London, London, UK

4 Neuropsychopharmacology Unit, Centre for Psychiatry, Division of Brain Sciences, Imperial College London, London, UK

5 Department of Neuroimaging, Institute of Psychiatry, Psychology and Neuroscience, King's College London, London, UK

\section{Introduction}

A leading hypothesis proposes that reduced gammaaminobutyric acid (GABA) signaling in frontotemporal brain regions underlies the pathogenesis of schizophrenia [1-3]. This hypothesis is supported by the postmortem literature showing that schizophrenia patients relative to controls show lower mRNA and protein levels of the synthetic enzyme GAD67 [4], lower levels of the GABA membrane transporter (GAT1) [5], and lower expression and cell density of GABAergic interneurons relative to controls $[3,6]$. In vivo studies have reported a reduction in concentrations of GABA in cerebrospinal fluid concentrations in first-episode psychotic patients [7]. By contrast proton magnetic resonance spectroscopy (1H-MRS) have yielded discrepant findings, potentially due to the technical difficulties in accurately resolving GABA on MRS spectra and its complex relationship with synaptic GABA [8,9]. GABA acts on two different subtypes of receptors, GABA$A$ and GABA-B. The GABA-A receptor is responsible for 
the majority of the physiological actions of GABA and it includes receptor subtypes made of different combinations of $\alpha, \beta, \gamma, \delta, \varepsilon, \mathrm{r}, \pi$, and $\theta$ subunits, organized in a pentameric structure arranged around a central pore [10].

The diversity in subunit composition and region-specific distribution allows GABA-A receptors to have distinct functional and physiological roles [11]. Studies using $\left[{ }^{11} \mathrm{C}\right]$ flumazenil and $\left[{ }^{123} I\right]$ iomazenil to index GABA receptor levels have not found differences between schizophrenia patients and healthy controls [12-15]. However, these radiotracers are not GABA subtype selective and show similar levels of uptake both in neocortex and limbic regions, which means they may be unable to detect differences in specific GABA receptor subtypes [16, 17]. In contrast, the inverse GABA-A receptor agonist $\left[{ }^{11} \mathrm{C}\right]$ Ro154513 is a radioligand that binds with ten times higher affinity $(\sim 0.5 \mathrm{nM})$ to the $\alpha 5$ subunit of the GABA receptor $(\alpha 5$ $\left.\mathrm{GABA}_{\mathrm{A}} \mathrm{Rs}\right)$ when compared with other subunits $(\sim 10 \mathrm{nM})$ $[16,18,19]$. Although $\alpha 5-\mathrm{GABA}_{\mathrm{A}}$ Rs represents $<5 \%$ of all GABA-A receptors [20], they are particularly concentrated in limbic regions [21]. In the hippocampus, a key brain region implicated in the pathogenesis of schizophrenia [22], $25 \%$ of GABA-A receptors are $\alpha 5-\mathrm{GABA}_{\mathrm{A}} \mathrm{Rs}$ [21]. Importantly, changes in $\alpha 5-\mathrm{GABA}_{\mathrm{A}} \mathrm{Rs}$ have been reported in schizophrenia patients, with postmortem studies showing lower mRNA and protein levels of this receptor $[23,24]$. Moreover, an $\alpha 5-\mathrm{GABA}_{\mathrm{A}} \mathrm{Rs}$ positive allosteric modulator (PAM) has been shown to reverse dopaminergic hyperactivation and behavioral sensitivity to psychostimulants in methylazoxymethanol (MAM)-treated animals, a preclinical model that reproduces many phenotypes seen in schizophrenia [25]. In contrast, the blockade of the $\alpha 5$ $\mathrm{GABA}_{\mathrm{A}}$ Rs impairs latent inhibition [26] and reduces prepulse inhibition to startle [27], behavioral phenotypes associated with schizophrenia. Whilst these converging lines of evidence implicate the $\alpha 5-\mathrm{GABA}_{\mathrm{A}} \mathrm{Rs}$ in schizophrenia, the only previous PET study using $\left[{ }^{11} \mathrm{C}\right]$ Ro $15-4513$ to assess $\alpha 5-\mathrm{GABA}_{\mathrm{A}}$ Rs availability showed no differences in binding potential (BP) between patients with schizophrenia and controls [28]. However, this study used a brain reference region approach, which is associated with an underestimation of BPs, and the potential confound of systematic differences in GABA availability in the reference region as well [29]. Therefore, it remains unclear if $\alpha 5-\mathrm{GABA}_{\mathrm{A}} \mathrm{Rs}$ availability is altered in schizophrenia patients in vivo when controlling for these methodological issues.

In view of this, we sought to investigate $\alpha 5-\mathrm{GABA}_{\mathrm{A}} \mathrm{Rs}$ availability in patients with schizophrenia using $\left[{ }^{11} \mathrm{C}\right]$ Ro154513 PET imaging with an arterial input function. We hypothesized that both medicated and antipsychotic-free schizophrenia patients would have lower GABA-A receptor availability in the hippocampus when compared with healthy controls, and that GABA-A receptor availability would be associated with symptom severity.

\section{Material and methods}

\section{Participants}

The study protocol was approved by the local Research Ethics Committee and the Administration of Radioactive Substances Advisory Committee, United Kingdom. All participants gave written informed consent prior to study participation. To control for potential sex differences in $\alpha 5$ $\mathrm{GABA}_{\mathrm{A}} \mathrm{Rs}$ availability [30] we specifically investigated male volunteers. Since antipsychotic medication may influence GABA function [31,32] we recruited two groups of patients, one taking antipsychotic treatment and the other antipsychotic free, and compared each group with matched healthy controls. Patients on antipsychotics were on a stable dose of antipsychotics for at least 4 weeks prior to the scan day. A total of 25 medicated patients with schizophrenia or schizoaffective disorder and 19 age-matched healthy controls were recruited. A further group of ten antipsychoticfree patients with schizophrenia or schizoaffective disorder and ten age-matched healthy controls were also recruited. All patients had capacity to give informed written consent and satisfied DSM-V diagnostic criteria for schizophrenia or schizoaffective disorder as determined by the Structured Clinical Interview for DSM-V-TR Axis I Disorders (SCID) [33].

All subjects had a physical and psychiatric examination. Urinalysis was done on the day of the scan to exclude the use of illicit drugs. Exclusion criteria for all participants included: female sex; history of head trauma or injury with loss of consciousness longer than one hour; learning disabilities or lack of English fluency; current or lifetime history of alcohol dependence; current or lifetime history of substance abuse or dependence; use of any recreational substances within the last month; current use or within the last month of psychotropic medication (other than an antipsychotic) with possible effects on the GABA system (such as antiepileptic drugs, benzodiazepines and antidepressants) [34] and contraindications to MRI or PET. Patients were excluded if treated with clozapine, diagnosed with an organic psychosis or had a history of neurological or psychiatric disorders other than schizophrenia, as assessed by the SCID [33]. Exclusion criteria for the antipsychotic-free patients included current or recent use of antipsychotics within the last 4 weeks or five half-lives of the drug (whichever was longer). The antipsychotic-free status was confirmed by reviewing clinical notes and pharmacy 
records. Healthy controls were administered the Psychosis Screening Questionnaire (PSQ) [35] and were excluded if they reported any psychotic symptom, history of psychotic illness or family history of psychosis. None of the healthy controls recruited to the study had a positive score in any of the PSQ questions.

Four patients recruited into the study were excluded from participation due to PET contraindications $(N=3)$ and commencement of clozapine treatment $(N=1)$. Therefore, the final analyses include 21 patients on antipsychotic mediation (medicated group) and 19 matched healthy controls and 10 antipsychotic-free patients (antipsychotic-free group) and 10 matched healthy controls.

\section{Clinical assessment}

Antipsychotic doses were converted into chlorpromazine equivalent dose as previously described [36]. Symptoms were evaluated using the Positive and Negative Syndrome Scale (PANSS) [37]. Duration of untreated psychosis was quantified as the interval between first psychotic symptoms and first contact with psychiatric services [38].

\section{Neuroimaging evaluation}

\section{Image acquisition}

Participants were instructed to refrain from alcohol for at least $12 \mathrm{~h}$ before scanning. Dynamic PET scans were acquired over 90 min using a Siemens ECAT EXACT HR (CTI/Siemens, model 962; Knoxville, TN, USA) scanner, with 63 trans-axial image planes covering an axial field of view of $15.5 \mathrm{~cm}$. PET emission data were corrected for attenuation and scatter using a 10-min transmission scan and reconstructed using Fourier rebinning and 2D filtered back projection with a $2.0 \mathrm{~mm}$ kernel Ramp filter, into 23 dynamic frames $(4 \times 15,4 \times 60,2 \times 150,10 \times 300$, and $3 \times$ $600 \mathrm{~s})$. The final reconstructed volume had voxel dimensions of $2.059 \times 2.059 \times 2.000 \mathrm{~mm}^{3}$.

During the PET acquisition, arterial blood data were sampled via the radial artery using a combined automaticmanual approach. A continuous sampling system (ABSS Allogg, Mariefred, Sweden) was employed to measure whole blood activity for first $15 \mathrm{~min}$ of each scan at the rate of one sample per second. Discrete blood samples were manually withdrawn at $2,5,10,15,20,25,30,40$, $50,60,70,80$, and $90 \mathrm{~min}$, centrifuged and used to determine the plasma over blood activity ratio (POB). Samples at 2, 5, and 10 min were used to calibrate the two sampling modalities. Samples taken at 2, 5, 10, 20, 30, 50, 70, and $90 \mathrm{~min}$ were also analyzed using HPLC to calculate the plasma fraction of tracer free of metabolites (PPf). Both POB and PPf were fitted with an extended
Hill model [39], while whole blood time-activity curves (TACs) were fitted using a multiexponential model [40] using the Multiblood software [41]. For each scan, a time delay was fitted and applied to the input functions (both parent and whole blood TACs) to account for the temporal delay between blood sample measurement and the target tissue data.

High resolution $\mathrm{T} 1$ weighted volumes were acquired using a 3T MR scanner (Magnetom Trio Syngo MR B13 Siemens 3T; Siemens AG, Germany) and a magnetization prepared rapid gradient echo sequence $(\mathrm{TR}=2300 \mathrm{~ms}$, $\mathrm{TE}=2.98 \mathrm{~ms}, \mathrm{TI}=900 \mathrm{~ms}$, flip angle $=9^{\circ}$, field of view $=$ $256 \mathrm{~mm}$, image matrix $=240 \times 256$ ) with a resolution of $1 \mathrm{~mm}$ isotropic. For the volume, 160 abutting straight sagittal slices were collected in an interleaved right to the left manner, resulting in whole head coverage.

\section{$\left[{ }^{11} \mathrm{C}\right] \mathrm{Ro} 15-4513$ PET data processing}

Dynamic PET data were corrected for interframe motion and aligned with the individual's structural T1 MR image by minimizing a mutual information cost function (SPM8, Wellcome Trust Centre for Neuroimaging, http://www.fil. ion.ucl.ac.uk/spm). A neuroanatomical atlas was also coregistered to each subject's image space (MIAKAT, http://www.imanova.co.uk) and applied to the dynamic PET data to derive regional TACs. The hippocampus was selected as our a priori region of interest since it has been implicated in the pathogenesis of schizophrenia and has a high expression of $\alpha 5$-GABA-A receptors relative to the rest of the brain, representing $25 \%$ of GABA-A receptors in this region [36]. Moreover, the quantification of the $\alpha 5$ subunit using $\left[{ }^{11} \mathrm{C}\right] \mathrm{Ro} 15-4513$ has been shown to be particularly reliable in the hippocampus (intraclass correlation coefficients (ICC) 0.9) [42]. GABA-A receptor availability was indexed using the distribution volume $\left(V_{\mathrm{T}}\right)$ of $\left[{ }^{11} \mathrm{C}\right]$ Ro15-4513. In agreement with previous publications [43, 44], the $V_{\mathrm{T}}$ was calculated using with the metabolite-free arterial plasma input function and the twotissue compartmental model (2TCM) solved with a nonlinear least squares approach for the regional level and the Logan graphical method at the voxel level [45].

\section{Statistical analysis}

Statistical analyses were performed with SPSS version 20 (IBM, Armonk, NY) for MAC OS X. The data distribution of all variables was tested using Kolmogorov-Smirnov tests and Grubbs test was used to determine if there were outlying data. Since all data were normally distributed, parametric tests were used. To test our primary hypothesis that GABA-A receptor availability would be altered in patients, an independent samples $t$-test was used to 
investigate if there were group differences in the $V_{\mathrm{T}}$ of $\left[{ }^{11} \mathrm{C}\right]$ Ro15-4513 in the hippocampus in (1) medicated patients relative to age-matched healthy controls and (2) antipsychotic-free patients relative to age-matched healthy volunteers. Independent samples $t$-tests were also used to investigate group differences in sociodemographic and clinical data. There was an outlier in the medicated patient group with high $V_{\mathrm{T}}$ values in the hippocampus (Grubbs test $p<0.05$ ) and these data were excluded from further analysis. To determine whether there was an effect of group on $V_{\mathrm{T}}$ values in our exploratory analyses of other brain regions, we performed a two-way ANOVA with $V_{\mathrm{T}}$ as the dependent variable and group (patient or control) and brain region as the independent variables. Exploratory analyses were also used to investigate the association between $\left[{ }^{11} \mathrm{C}\right] \mathrm{Ro} 15$ 4513 and clinical data using Pearson's product moment correlation. All data are presented as mean $\pm \mathrm{SD}$, and the $\alpha$ level was set for all comparisons at $p<0.05$, corrected.

\section{Results}

\section{Demographic and clinical characteristics of study participants}

Four groups of participants were included in the study: twenty-one patients taking antipsychotic mediation (medicated group) and nineteen matched healthy controls and ten antipsychotic-free patients (antipsychotic-free group) and ten matched healthy controls. In the medicated group, 19 patients had a diagnosis of schizophrenia and 2 patients had a diagnosis of schizoaffective disorder. No patient had any comorbid psychiatric diagnosis as assessed by the SCID. Only one patient was taking a first-generation antipsychotic, while the remaining 20 patients were taking a secondgeneration antipsychotic drug (Supplementary Data, Table S1). All of the patients in the antipsychotic-free group had a diagnosis of schizophrenia and were antipsychoticfree for a period of at least 4 weeks or five half-lives of the drug (whichever was longer).

The demographic and clinical characteristics of the subjects are presented in Table 1 . There were no group differences in any sociodemographic variables, or injected dose, injected mass or specific activity in medicated and antipsychotic-free patients and their respective healthy control groups.

\section{Hippocampus a5-GABA $A_{A} R$ availability in patients and controls}

There was significantly lower $\left[{ }^{11} \mathrm{C}\right] \mathrm{Ro} 15-4513 \quad V_{\mathrm{T}}$ in the hippocampus of antipsychotic-free patients when compared with healthy controls (mean \pm SD: $6.90 \pm 0.56$ vs. $7.68 \pm 0.54$, respectively, $p=0.006$, effect size $=1.4$; Figs. 1 and 2).

In contrast there was no significant group difference in the $\left[{ }^{11} \mathrm{C}\right]$ Ro15-4513 $V_{\mathrm{T}}$ between the medicated patients and healthy controls (mean \pm SD: $6.94 \pm 0.62$ vs. $7.06 \pm 0.86$, $p=0.64$ ) (Fig. 3). There was also no significant difference in $\alpha 5-G_{A B A}$ Rs availability between the medicated and antipsychotic-free schizophrenia groups $(p=0.54)$.

Table 1 Demographic and clinical characteristics of the medicated and antipsychotic-free schizophrenia patients and their healthy comparison subjects.

\begin{tabular}{|c|c|c|c|c|c|c|c|c|c|c|}
\hline & \multicolumn{2}{|c|}{$\begin{array}{l}\text { Medicated } \\
\text { patients } \\
(n=21)\end{array}$} & \multicolumn{2}{|c|}{$\begin{array}{l}\text { Healthy } \\
\text { controls } \\
(n=19)\end{array}$} & \multirow{2}{*}{$\begin{array}{l}\text { Test statistic } \\
p\end{array}$} & \multicolumn{2}{|c|}{$\begin{array}{l}\text { Antipsychotic- } \\
\text { free patients } \\
(n=10)\end{array}$} & \multicolumn{2}{|c|}{$\begin{array}{l}\text { Healthy } \\
\text { controls } \\
(n=10)\end{array}$} & \multirow{2}{*}{$\begin{array}{l}\text { Test statistic } \\
p\end{array}$} \\
\hline & Mean & SD & Mean & SD & & Mean & SD & Mean & SD & \\
\hline Age at scan (mean years, SD) & 37.2 & 10.95 & 42.2 & 7.27 & 0.102 & 24.1 & 3.17 & 26.3 & 1.49 & 0.06 \\
\hline Handedness: right-handed (\%) & $100 \%$ & & $100 \%$ & & 1 & $100 \%$ & & $100 \%$ & & 1 \\
\hline PANSS total score & 65.6 & 14.35 & $\mathrm{n} / \mathrm{a}$ & $\mathrm{n} / \mathrm{a}$ & $\mathrm{n} / \mathrm{a}$ & 56.5 & 16.3 & $\mathrm{n} / \mathrm{a}$ & $\mathrm{n} / \mathrm{a}$ & $\mathrm{n} / \mathrm{a}$ \\
\hline Duration of illness (months) & 110.4 & 84.1 & $\mathrm{n} / \mathrm{a}$ & $\mathrm{n} / \mathrm{a}$ & $\mathrm{n} / \mathrm{a}$ & 32.1 & 33.6 & $\mathrm{n} / \mathrm{a}$ & $\mathrm{n} / \mathrm{a}$ & $\mathrm{n} / \mathrm{a}$ \\
\hline Medication dosage (CPZ equivalents) & 328.1 & 160.1 & $\mathrm{n} / \mathrm{a}$ & $\mathrm{n} / \mathrm{a}$ & $\mathrm{n} / \mathrm{a}$ & $\mathrm{n} / \mathrm{a}$ & $\mathrm{n} / \mathrm{a}$ & $\mathrm{n} / \mathrm{a}$ & $\mathrm{n} / \mathrm{a}$ & $\mathrm{n} / \mathrm{a}$ \\
\hline Radioactivity dose (MBq) & 353.4 & 79.4 & 365.8 & 59.0 & 0.58 & 334.9 & 67.3 & 319.3 & 80.3 & 0.64 \\
\hline Specific activity $(\mathrm{GBq} / \mu \mathrm{mol})$ & 36.1 & 12.5 & 42.0 & 17.0 & 0.21 & 36.5 & 13.3 & 45.1 & 17.0 & 0.22 \\
\hline Injected mass $(\mu \mathrm{g})$ & 3.69 & 1.9 & 3.38 & 1.69 & 0.58 & 2.80 & 1.97 & 3.18 & 1.78 & 0.45 \\
\hline Total hippocampal volume $\left(\mathrm{mm}^{3}\right)$ & 10380 & 1012 & 10952 & 1245 & 0.18 & 10708 & 1270 & 10925 & 1191 & 0.69 \\
\hline Left hippocampal volume $\left(\mathrm{mm}^{3}\right)$ & 4040 & 400 & 4238 & 477 & 0.16 & 3952 & 1344 & 4361 & 371 & 0.36 \\
\hline Right hippocampal volume $\left(\mathrm{mm}^{3}\right)$ & 3839 & 492 & 3935 & 420 & 0.51 & 3672 & 1257 & 4270 & 599 & 0.19 \\
\hline
\end{tabular}

$S D$ standard deviation, $C P Z$ chlorpromazine, n.a. not applicable. 


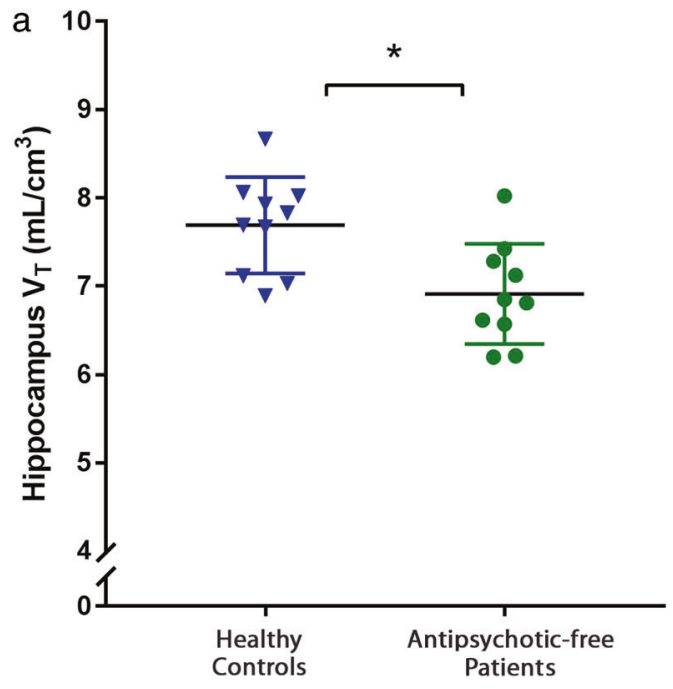

Fig. 1 Volume of distribution (VT) values of [11C]Ro15-4513 in the hippocampus by group for antipsychotic-free patients (with mean \pm SD). There was significantly lower [11C]Ro15-4513 volume of distribution (VT) in the hippocampus in antipsychotic-free patients

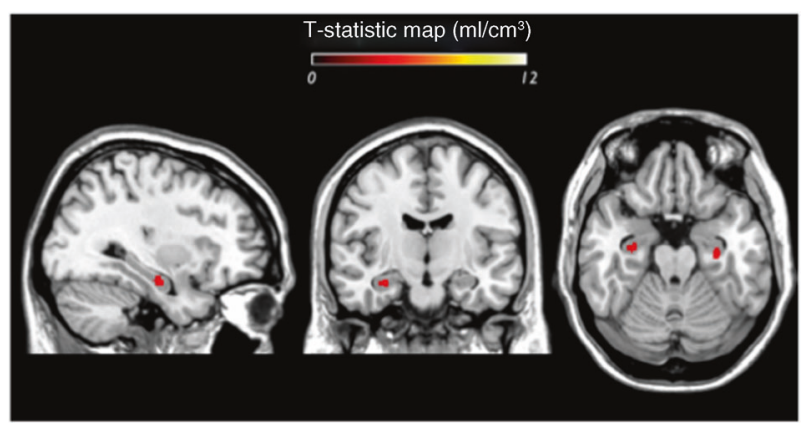

Fig. 2 Voxelwise T-static maps showing regions within the hippocampus where $V_{\mathrm{T}}$ is significantly lower in antipsychotic-free patients relative to controls (threshold $\boldsymbol{p}=\mathbf{0 . 0 5}$ uncorrected for illustration purposes). Images are in MNI space (voxel size: $2 \mathrm{~mm} \times$ $2 \mathrm{~mm} \times 2 \mathrm{~mm}$ ). The hippocampal mask included 1573 voxels.

\section{Correlations between hippocampus a5-GABA ${ }_{A} R s$ availability and clinical characteristics}

We found no significant correlation between $\left[{ }^{11} \mathrm{C}\right]$ Ro $15-4513$ $V_{\mathrm{T}}$ and the exposure to antipsychotics, as measured in chlorpromazine equivalents doses $(r=0.32 ; p=0.22)$. There was also no significant correlation with $V_{\mathrm{T}}$ and duration of illness in either the antipsychotic-free $(r=0.105 ; p=0.78)$ or the medicated $(r=-0.02 ; p=0.91)$ groups. In the antipsychotic-free patient group, there was a significant positive correlation between $\left[{ }^{11} \mathrm{C}\right]$ Ro15-4513 $V_{\mathrm{T}}$ and severity of symptoms, as assessed by the total PANSS score $(r=0.72$; $p=0.044$ ) (Fig. 4), which was not significant in the medicated patient group $(r=0.22 ; p=0.38)$. There was also no significant correlation between $\left[{ }^{11} \mathrm{C}\right] \mathrm{Ro} 15-4513 V_{\mathrm{T}}$ and age in

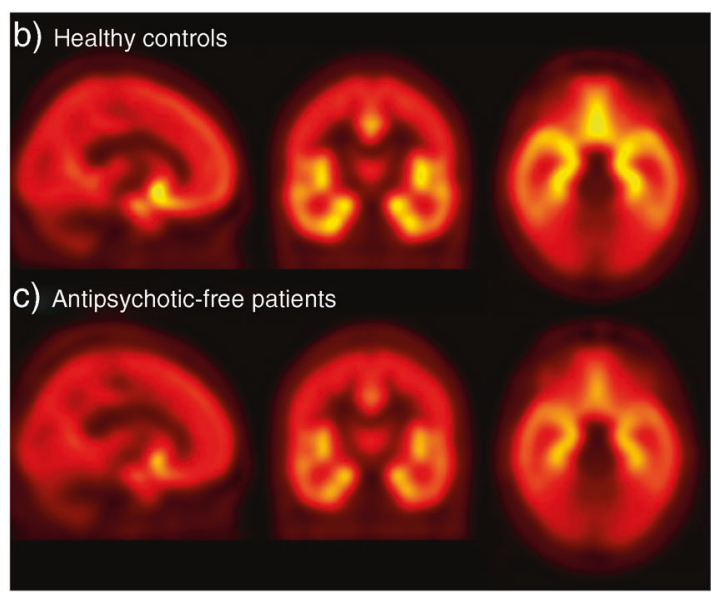

with schizophrenia relative to healthy controls $\left({ }^{*} p<0.05\right.$; effect size $=1.4$ ). Group average VT parametric maps showing sagittal, coronal, and transverse images (from left to right) for: b healthy controls and $\mathbf{c}$ antipsychotic-free schizophrenia patients.

either the medicated $(r=-0.20 ; p=0.19)$ or the antipsychotic-free $(r=0.16 ; p=0.49)$ groups.

\section{Hippocampus volume}

There were no significant differences in hippocampal volumes between antipsychotic-free patients relative to healthy controls and between medicated patients and healthy controls (Table 1). There were also no significant correlations between hippocampal volumes and the $\left[{ }^{11} \mathrm{C}\right] \mathrm{Ro} 15-$ $4513 V_{\mathrm{T}}$ in the hippocampus in either antipsychotic-free patients $(r=-0.035 ; p=0.92)$ or medicated patients $(r=$ $1.99 ; p=0.38)$

\section{Other brain regions}

In antipsychotic-free patients relative to healthy controls, there was a significant main effect of group on $V_{\mathrm{T}}$ measures across all ROIs $(F(1,144)=5.73, p=0.01)$. There was also a significant main effect of region on $V_{\mathrm{T}}$ measures across all ROIs $(F(7,144)=179, p<0.001)$. However, the group $\times$ region interaction was not significant $(F(7,144)=$ $0.61, p=0.74)$, and there were no significant differences in the posthoc pair-wise comparisons for individual regions (Supplementary Data, Table S2). In the medicated patient group, there was no significant effect of group on $V_{\mathrm{T}}$ measures across all ROIs $(F(1,304)=0.50, p=0.47)$. However, there was a significant main effect of region on $V_{\mathrm{T}}$ across the brain $(F(7,304)=161, p<0.001)$ but the group $\times$ region interaction was not significant $(F(7,304)=$ $0.94, p=0.47)$, and there were no significant differences in 


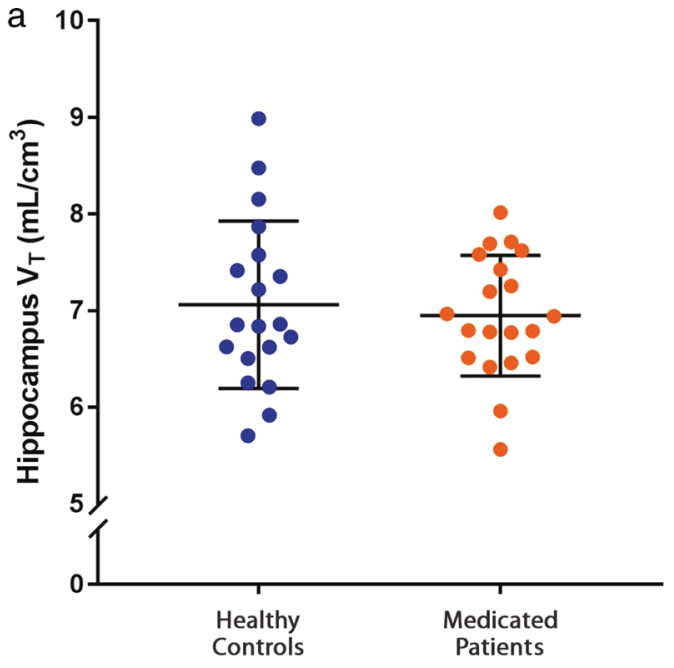

Fig. 3 Volume of distribution $\left(V_{\mathrm{T}}\right)$ values of $\left[{ }^{11} \mathrm{C}\right] \mathrm{Ro15-4513}$ in the hippocampus in medicated patients and healthy controls. a Scatter plots showing the volume of distribution $\left(V_{\mathrm{T}}\right)$ values of $\left[{ }^{11} \mathrm{C}\right] \mathrm{Ro} 15$ 4513 in the hippocampus by group for medicated patients (with mean $\pm \mathrm{SD}$ ). There were no significant differences between medicated

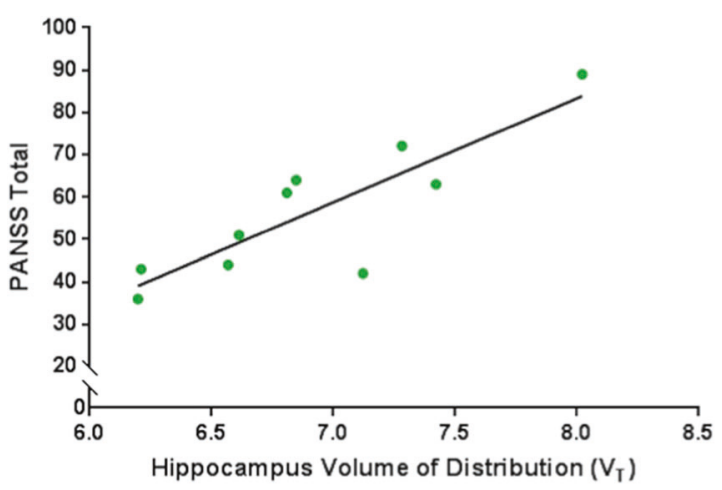

Fig. 4 Correlation between volume of distribution $\left(V_{T}\right)$ values of $\left[{ }^{11} \mathrm{C}\right] \mathrm{Ro15}-4513$ in the hippocampus and total PANSS symptom severity scores in antipsychotic-free patients with schizophrenia. There was a significant positive correlation between hippocampal $V_{\mathrm{T}}$ and symptom severity $(r=0.72 ; p<0.05)$.

the posthoc pair-wise comparisons for individual regions (Supplementary Data, Table S2).

\section{Discussion}

Our results show that GABA-A receptor availability, measured with a tracer selective for the $\alpha 5$-GABA-A receptor subunit, is significantly lower in the hippocampi of antipsychotic-free schizophrenia patients, and directly correlated with symptom severity. However, $\alpha 5-G_{A B A}$ Rs availability is not significantly altered in antipsychotictreated patients when compared with controls.

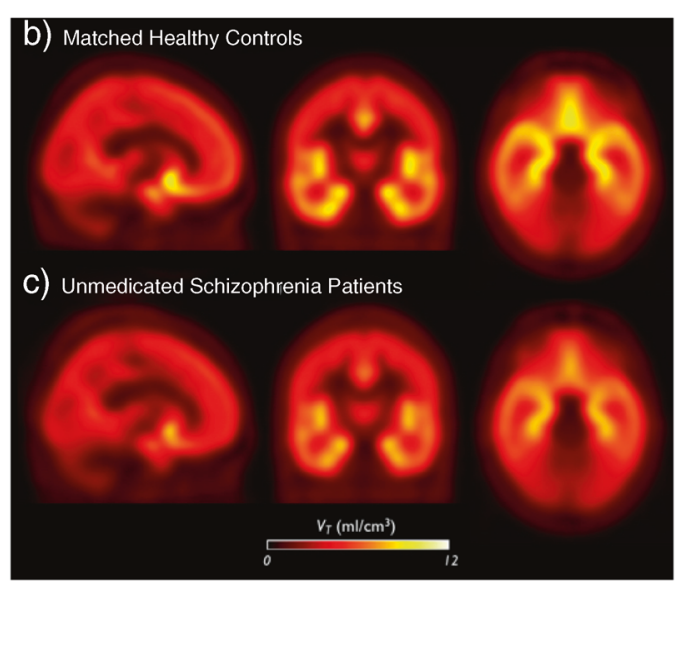

patients with schizophrenia and healthy controls. Group average $V_{\mathrm{T}}$ parametric maps showing sagittal, coronal, and transverse images (from left to right) for: $\mathbf{b}$ healthy controls and $\mathbf{c}$ antipsychotic-free schizophrenia patients.

Our results extend postmortem findings showing lower mRNA and protein levels of $\alpha 5-\mathrm{GABA}_{\mathrm{A}} \mathrm{Rs}$ in schizophrenia patients $[23,24]$ to show evidence for lower hippocampal uptake of an $\alpha 5-\mathrm{GABA}_{\mathrm{A}} \mathrm{Rs}$ selective tracer in vivo in untreated patients with schizophrenia. However, our results are not consistent with the only previous $\left[{ }^{11} \mathrm{C}\right]$ Ro15-4513 PET study in schizophrenia patients [28], where no differences in $\left[{ }^{11} \mathrm{C}\right]$ Ro15-4513 BP were observed between antipsychotic-free patients and healthy controls. The lack of group effects in this previous study may be due to the use of simplified reference tissue model (SRTM) with the pons as the reference tissue to quantify $\left[{ }^{11} \mathrm{C}\right]$ Ro15-4513 BP. This approach relies on a number of assumptions which can easily lead to biased estimates if violated [46]. Moreover, the ICC across brain regions range between 0.35 and 0.80 when using SRTM, which indicates lower reliability than the approach we used, where ICC values are $>0.82$ $[42,47]$. The use of the pons as a reference region for $\left[{ }^{11} \mathrm{C}\right]$ Ro15-4513 PET has also been subject to criticism, since it may lead to the underestimation of target binding $[19,46,47]$. For these reasons, the SRTM approach used in the Asai et al. study may have lacked sensitivity to detect group differences.

Interestingly, our study showed no significant differences in $\left[{ }^{11} \mathrm{C}\right]$ Ro15-4513 $V_{\mathrm{T}}$ in medicated schizophrenia patients when compared with controls. Taken with our findings in the antipsychotic-free patients and other findings of lower GABA-A receptor prior to treatment [48], these results could suggest that there has been a normalization of $\alpha 5$ $\mathrm{GABA}_{\mathrm{A}}$ Rs levels with antipsychotic treatment. In addition, reduced GABA release, as assessed using a tiagabine 
challenge, was seen in antipsychotic-naive individuals but not in antipsychotic-treated patients [15]. Previous literature has also shown evidence of altered GABA levels using $1 \mathrm{H}-\mathrm{MRS}$ in unmedicated patients but not in medicated patients [32]. Moreover, 4 weeks of exposure to antipsychotic treatment has also been found to normalize GABA levels in patients [32]. Post-mortem studies also find differences between treated and untreated patients with schizophrenia, showing a positive correlation between the density of GAD and antipsychotic dose and higher expression levels of GAD67 and GABA-A protein subunits in antipsychotic-treated patients relative to unmedicated patients [49]. However, it is important to note that both in our study and in these prior studies, the antipsychotictreated group had a longer duration of illness than the untreated group. As such, it is not possible to disentangle duration of illness from treatment effects. However, in our study, we found no significant associations between $\alpha 5-\mathrm{GABA}_{\mathrm{A}} \mathrm{Rs}$ availability and duration of illness, indicating that antipsychotic treatment could contribute to the lack of group differences in the treated patients. This is supported by preclinical findings showing an increased expression of GAD67 and increased GABA-A receptor binding in rats exposed to a range of different antipsychotics [50] and by clinical studies showing that exposure to 4 weeks of antipsychotic treatment normalizes GABA levels in schizophrenia patients [32]. However, longitudinal studies in patients are needed to test the hypothesis that there are changes in GABA-A receptor levels over time and if they are associated to exposure to antipsychotic medication.

\section{Strengths and limitations}

A strength of the study was that we included a large sample for a PET study and obtained arterial input functions [19]. In our study, we used the 2TCM model, which has been shown to have good reliability for $\left[{ }^{11} \mathrm{C}\right] \mathrm{Ro} 15-4513$ quantification (ICC ranging from 0.83 to 0.88 ), and $V_{\mathrm{T}}$ values derived from this model show a close, linear relationship with $\alpha 5$ $\mathrm{GABA}_{\mathrm{A}} \mathrm{Rs}$ specific binding [19]. One potential limitation on generalizability is that we only included males, as there are sex differences in GABA-A receptor expression [30]. Future studies are needed to test if our findings generalize to female patients as well. Although both groups are matched for age, there is a trend level difference in age between antipsychoticfree patients and healthy controls $(p=0.06)$. Importantly, the $V_{\mathrm{T}}$ values in our healthy control cohorts are similar to the ones reported in other studies using the [11C]Ro15-4513 PET tracer [51,43], indicating that our findings are not driven by abnormal values in our controls. Furthermore, $\alpha 5$-GABAARs show developmental reductions and, supporting this, in healthy volunteers there is an inverse relationship between age and $\left[{ }^{11} \mathrm{C}\right]$ Ro15-4513 $V_{\mathrm{T}}$ values. The lack of group differences in the chronic patients taken with the lower $V_{\mathrm{T}}$ values could suggest disruption of the normal age-related reductions in $\alpha 5$-GABAARs. The antipsychotic-free period in the antipsychotic-free group was 4 weeks or over five half-lives (whichever was longer), and no antipsychotic taken in the medicated group has significant affinity for GABA-A receptors (all Ki values $>10,000$ ) [52-55], indicating that direct effects of antipsychotic drugs on GABA-A receptors are unlikely to explain our findings. We did not find any significant difference in hippocampal volume, suggesting that partial volume effects are unlikely to account for our group differences. Furthermore, although a reduction in hippocampus volume in schizophrenia is commonly reported [56], in our study there were no significant volumetric differences in hippocampal volume between patients and controls. This can be explained by the hippocampus being one of the brain areas with greater structural variability [57]. Finally, $\left[{ }^{11} \mathrm{C}\right]$ Ro15-4513 is a highly selective $\alpha 5-\mathrm{GABA}_{\mathrm{A}}$ Rs PET radiotracer, with $\alpha 5$ representing around $60-70 \%$ of the specific binding in $\alpha 5$ rich regions [19], and its affinity for this subunit is $\sim 10$ - to 20 -fold greater than to other subtypes of the GABA-A receptor [16, 17]. However, it also demonstrates measurable in vivo binding for the $\alpha 1$ to $\alpha 4$ and $\alpha 6$ receptor subtypes [16, 17]. Overall, although the $\left[{ }^{11} \mathrm{C}\right] \mathrm{Ro} 15-4513 V_{\mathrm{T}}$ reflects the net effect of the availability of these different GABA-A receptors, the 20-fold greater affinity of $\left[{ }^{11} \mathrm{C}\right]$ Ro 15 4513 for $\alpha 5-\mathrm{GABA}_{\mathrm{A}} \mathrm{Rs}$ and the enriched expression of $\alpha 5$ $\mathrm{GABA}_{A} \mathrm{Rs}$ in the hippocampus indicates the lower $\left[{ }^{11} \mathrm{C}\right]$ Ro15-4513 hippocampal availability is likely to predominantly reflect lower $\alpha 5-\mathrm{GABA}_{\mathrm{A}} \mathrm{R}$ levels.

\section{The interpretation of the findings and their implications for understanding schizophrenia}

GABAergic neurotransmission in the hippocampus plays a fundamental role in inhibiting the neuronal activity of pyramidal glutamatergic cells, through the activation of postsynaptic GABA receptors $[58,59]$. The hippocampus has a particularly high concentration of $\alpha 5-\mathrm{GABA}_{\mathrm{A}} \mathrm{Rs}$ relative to other brain regions, constituting up to $25 \%$ of all GABA-A receptors in the hippocampus. Although other receptor subtypes are also present [60], $\alpha 5$ represents around $60-70 \%$ of the specific binding of $\left[{ }^{11} \mathrm{C}\right] \mathrm{Ro} 15-4513$ in the hippocampus $[19,61]$. While $\alpha 1$ and $\alpha 2-G_{A B A}{ }_{A}$ Rs are located synaptically and involved in the phasic inhibition of pyramidal cells, $\alpha 5-\mathrm{GABA}_{\mathrm{A}} \mathrm{Rs}$ are located mainly at extrasynaptic sites $[19,62]$. At these sites, $\alpha 5-\mathrm{GABA}_{\mathrm{A}} \mathrm{Rs}$ are predominantly involved in generating a tonic inhibitory current [63-65] to regulate the excitability of pyramidal neurons $[66,67]$ and decrease network excitability. Interestingly, this tonic inhibition has been shown to be at least equally important in the regulation of pyramidal cells firing as phasic inhibition [63]. 
$\alpha 5-G_{A B A} R_{A}$ s deficient mice show reduced tonic inhibition resulting in hippocampus hyperexcitability, which can be reversed by pharmacologically increasing the tonic current [67]. The lower $\alpha 5-\mathrm{GABA}_{\mathrm{A}}$ receptor levels we observe may therefore contribute to reductions in tonic inhibition, leading to an increase in hippocampal hyperexcitability. This interpretation is supported by the previous literature implicating the hippocampus in the pathophysiology of schizophrenia including changes in hippocampal volume [68] as well as changes in regional cerebral blood flow [69] and blood oxygen level-dependent signal [70]. Taken together these suggest that lower $\alpha 5-G A B A_{A}$ Rs levels could lead to a state of excessive excitation [59, 62]. Our findings are therefore consistent with hypotheses that a reduction in GABAergic neurotransmission disinhibits glutamatergic pyramidal neurons, resulting in the loss of synchronous cortical activity, and subcortical dopamine dysregulation. Furthermore, the activation of $\alpha 5-\mathrm{GABA}_{\mathrm{A}}$ Rs by a PAM has been shown to reverse the dopaminergic and behavioral abnormalities observed in the MAM model [25-27]. These findings highlight the therapeutic potential of targeting GABA function in schizophrenia [1,59]. We found a significant positive correlation between $\alpha 5-\mathrm{GABA}_{\mathrm{A}} \mathrm{Rs}$ availability and symptom severity in antipsychotic-free patients. Whilst this supports a link between $\alpha 5-\mathrm{GABA}_{\mathrm{A}} \mathrm{Rs}$ dysregulation and the clinical expression of the disorder, the direction of the association is not consistent with a simple model of $\alpha 5-\mathrm{GABA}_{\mathrm{A}} \mathrm{Rs}$ hypofunction leading to hippocampal overactivity and symptoms. It was recently shown, using a viral-mediated gene transfer, that an increase in the expression of $\alpha 5-G_{A B A}$ Rs normalizes VTA dopamine cell population activity [71]. Thus, one explanation that could account for both the lower [11C] Ro15-4513 binding in patients and a positive correlation with symptoms is that low $\alpha 5-\mathrm{GABA}_{\mathrm{A}} \mathrm{R}$ levels are a vulnerability factor but that once the disorder develops there is a compensatory increase in $\alpha 5-\mathrm{GABA}_{\mathrm{A}} \mathrm{R}$ levels in response to dysregulation of other systems. This is consistent with the role of $\alpha 5-\mathrm{GABA}_{\mathrm{A}} \mathrm{Rs}$ in providing tonic regulation of pyramidal neurons [72]. A longitudinal study is needed to test this model further. Finally, our exploratory analysis in other brain regions also showed a significant difference between antipsychotic-free patients and controls in the omnibus test, suggesting there may be GABA-A receptor alterations in other brain regions in schizophrenia. However, no individual region was significantly different in the pair-wise comparisons, which could reflect the fact that the expression of $\alpha 5$ $\mathrm{GABA}_{\mathrm{A}} \mathrm{Rs}$ is lower in these regions [33].

\section{Conclusions and future directions}

This study provides evidence that antipsychotic-free patients with schizophrenia have lower GABA-A receptors in the hippocampus, predominantly of the alpha-5 subtype, that is not seen in antipsychotic-treated patients. These findings are consistent with the hypothesis that GABA hypofunction underlies the pathophysiology of the disorder, and highlights the potential of GABAergic modulators as therapeutic targets for schizophrenia [72].

Funding This study was funded by grants MC-A656-5QD30 from the Medical Research Council-UK, 666 from the Maudsley Charity 094849/Z/10/Z from the Brain and Behavior Research Foundation, and Wellcome Trust to ODH.

\section{Compliance with ethical standards}

Conflict of interest TRM conducts research funded by the Medical Research Council (UK) and King's College London. TRM have received honoraria for speaking and chairing engagements from Lundbeck, Janssen, and Astellas. ODH conducts research funded by the Medical Research Council (UK), the National Institute of Health Research (UK), and the Maudsley Charity. ODH has received investigator-initiated research funding from and/or participated in advisory/speaker meetings organized by Astra-Zeneca, BMS, Eli Lilly, Jansenn, Lundbeck, Lyden-Delta, Servier, and Roche. Neither ODH nor his family has been employed by or has holdings/a financial stake in any biomedical company. AL-H has received honoraria paid into her institutional funds for speaking and chairing engagements from Lundbeck, Lundbeck Institute UK, Janssen-Cilag, Pfizer, Servier; received research grants or support from Lundbeck, GSK; consulted by Silence, NET Device Corps, Sanofi-Aventis, and also consulted by but received no monies from Britannia Pharmaceuticals, GLG, Opiant, Lightlake, and Dobrin. JM has received travel funds from Roche. MV is supported by the National Institute for Health Research (NIHR) Biomedical Research Centre at South London and Maudsley NHS Foundation Trust and King's College London. Prof. Turkheimer, AHA, FB, and Miss IA report no financial relationships with commercial interests.

Publisher's note Springer Nature remains neutral with regard to jurisdictional claims in published maps and institutional affiliations.

Open Access This article is licensed under a Creative Commons Attribution 4.0 International License, which permits use, sharing, adaptation, distribution and reproduction in any medium or format, as long as you give appropriate credit to the original author(s) and the source, provide a link to the Creative Commons license, and indicate if changes were made. The images or other third party material in this article are included in the article's Creative Commons license, unless indicated otherwise in a credit line to the material. If material is not included in the article's Creative Commons license and your intended use is not permitted by statutory regulation or exceeds the permitted use, you will need to obtain permission directly from the copyright holder. To view a copy of this license, visit http://creativecommons. org/licenses/by/4.0/.

\section{References}

1. Coyle JT. The GABA-glutamate connection in schizophrenia: which is the proximate cause? Biochem Pharmacol. 2004;68:1507-14.

2. Grace AA. Dopamine system dysregulation by the hippocampus: implications for the pathophysiology and treatment of schizophrenia. Neuropharmacology. 2012;62:1342-8. 
3. Lewis DA, Curley AA, Glausier JR, Volk DW. Cortical parvalbumin interneurons and cognitive dysfunction in schizophrenia. Trends Neurosci. 2012;35:57-67.

4. Curley AA, Arion D, Volk DW, Asafu-Adjei JK, Sampson AR, Fish KN, et al. Cortical deficits of glutamic acid decarboxylase 67 expression in schizophrenia: clinical, protein, and cell typespecific features. Am J Psychiatry. 2011;168:921-9.

5. Volk D, Austin M, Pierri J, Sampson A, Lewis D. GABA transporter-1 mRNA in the prefrontal cortex in schizophrenia: decreased expression in a subset of neurons. Am J Psychiatry. 2001;158:256-65.

6. Sakai T, Oshima A, Nozaki Y, Ida I, Haga C, Akiyama H, et al. Changes in density of calcium-binding-protein-immunoreactive GABAergic neurons in prefrontal cortex in schizophrenia and bipolar disorder. Neuropathology. 2008;28:143-50.

7. Orhan F, Fatouros-Bergman H, Goiny M, Malmqvist A, Piehl F, Karolinska Schizophrenia Project (KaSP) Consortium. et al. CSF GABA is reduced in first-episode psychosis and associates to symptom severity. Mol Psychiatry. 2018;23:1244-50.

8. Poels EM, Kegeles LS, Kantrowitz JT, Slifstein M, Javitt DC, Lieberman JA, et al. Imaging glutamate in schizophrenia: review of findings and implications for drug discovery. Mol Psychiatry. 2014;19:20-9.

9. Egerton A, Modinos G, Ferrera D, McGuire P. Neuroimaging studies of GABA in schizophrenia: a systematic review with metaanalysis. Transl Psychiatry. 2017;7:e1147.

10. Nutt DJ, Malizia AL. New insights into the role of the GABA(A)benzodiazepine receptor in psychiatric disorder. Br J Psychiatry. 2001;179:390-6.

11. Mody I, Pearce RA. Diversity of inhibitory neurotransmission through GABA(A) receptors. Trends Neurosci. 2004;27:569-75.

12. Busatto GF, Pilowsky LS, Costa DC, Ell PJ, David AS, Lucey JV, et al. Correlation between reduced in vivo benzodiazepine receptor binding and severity of psychotic symptoms in schizophrenia. Am J Psychiatry. 1997;154:56-63.

13. Abi-Dargham A, Laruelle M, Krystal J, D’Souza C, Zoghbi S, Baldwin RM, et al. No evidence of altered in vivo benzodiazepine receptor binding in schizophrenia. Neuropsychopharmacology. 1999;20:650-61.

14. Lee JS, Lee JD, Park HJ, Oh MK, Chun JW, Kim SJ, et al. Is the GABA system related to the social competence improvement effect of aripiprazole? An (18)F-fluoroflumazenil PET study. Psychiatry Investig. 2013;10:75-80.

15. Frankle WG, Cho RY, Prasad KM, Mason NS, Paris J, Himes $\mathrm{ML}$, et al. In vivo measurement of GABA transmission in healthy subjects and schizophrenia patients. Am J Psychiatry. 2015;172:1148-59.

16. Sieghart W. Structure and pharmacology of gamma-aminobutyric acid A receptor subtypes. Pharm Rev. 1995;47:181-234.

17. Hammers A. Flumazenil positron emission tomography and other ligands for functional imaging. Neuroimaging Clin N. Am. 2004;14:537-51.

18. Lingford-Hughes A, Hume SP, Feeney A, Hirani E, Osman S, Cunningham VJ, et al. Imaging the GABA-benzodiazepine receptor subtype containing the alpha5-subunit in vivo with [11C]Ro15 4513 positron emission tomography. J Cereb Blood Flow Metab. 2002;22:878-89.

19. Myers JF, Comley RA, Gunn RN. Quantification of [11C]Ro154513 GABAA $\alpha 5$ specific binding and regional selectivity in humans. J Cereb Blood Flow Metab. 2017;37:2137-48.

20. McKernan RM, Whiting PJ. Which GABAA-receptor subtypes really occur in the brain? Trends Neurosci. 1996;19:139-43.

21. Sur C, Fresu L, Howell O, McKernan RM, Atack JR. Autoradiographic localization of alpha5 subunit-containing GABAA receptors in rat brain. Brain Res. 1999;822:265-70.
22. Benes FM, Lim B, Matzilevich D, Walsh JP, Subburaju S, Minns M. Regulation of the GABA cell phenotype in hippocampus of schizophrenics and bipolars. Proc Natl Acad Sci USA. 2007; 104:10164-9.

23. Beneyto M, Abbott A, Hashimoto T, Lewis DA. Lamina-specific alterations in cortical $\mathrm{GABA}(\mathrm{A})$ receptor subunit expression in schizophrenia. Cereb Cortex. 2011;21:999-1011.

24. Duncan CE, Webster MJ, Rothmond DA, Bahn S, Elashoff M, Shannon Weickert C. Prefrontal GABA(A) receptor alpha-subunit expression in normal postnatal human development and schizophrenia. J Psychiatr Res. 2010;44:673-81.

25. Gill KM, Lodge DJ, Cook JM, Aras S, Grace AA. A novel alpha5GABA(A)R-positive allosteric modulator reverses hyperactivation of the dopamine system in the MAM model of schizophrenia. Neuropsychopharmacology. 2011;36:1903-11.

26. Gerdjikov TV, Rudolph U, Keist R, Mohler H, Feldon J, Yee BK. Hippocampal alpha 5 subunitcontaining GABA A receptors are involved in the development of the latent inhibition effect. Neurobiol Learn Mem. 2008;89:87-94.

27. Hauser J, Rudolph U, Keist R, Mohler H, Feldon J, Yee BK. Hippocampal alpha5 subunit containing GABAA receptors modulate the expression of prepulse inhibition. Mol Psychiatry. 2005;10:201-7.

28. Asai Y, Takano A, Ito H, Okubo Y, Matsuura M, Otsuka A, et al. GABAA/Benzodiazepine receptor binding in patients with schizophrenia using [11C]Ro15-4513, a radioligand with relatively high affinity for alpha5 subunit. Schizophr Res. 2008;99:333-40.

29. Veronese M, Zanotti-Fregonara P, Rizzo G, Bertoldo A, Innis RB, Turkheimer FE. Measuring specific receptor binding of a PET radioligand in human brain without pharmacological blockade: the genomic plot. Neuroimage. 2016;130:1-12.

30. Bristow GC, Bostrom JA, Haroutunian V, Sodhi MS. Sex differences in GABAergic gene expression occur in the anterior cingulate cortex in schizophrenia. Schizophr Res. 2015; 167:57-63.

31. Tayoshi S, Nakataki M, Sumitani S, Taniguchi K, ShibuyaTayoshi S, Numata S, et al. GABA concentration in schizophrenia patients and the effects of antipsychotic medication: a proton magnetic resonance spectroscopy study. Schizophr Res. 2010;117:83-91.

32. de la Fuente-Sandoval C, Reyes-Madrigal F, Mao X, León-Ortiz $\mathrm{P}$, Rodríguez-Mayoral $\mathrm{O}$, Jung-Cook $\mathrm{H}$, et al. Prefrontal and striatal gamma-aminobutyric acid levels and the effect of antipsychotic treatment in first-episode psychosis patients. Biol Psychiatry. 2018;83:475-83.

33. First MB, Spitzer RL, Gibbon M, Williams JBW. Structured clinical interview for DSM-IV-TR axis I disorders, research version, patient edition. (SCID-I/P). New York: Biometrics Research, New York State Psychiatric Institute, 2002.

34. Bhagwagar Z, Wylezinska M, Taylor M, Jezzard P, Matthews PM, Cowen PJ. Increased brain GABA concentrations following acute administration of a selective serotonin reuptake inhibitor. Am J Psychiatry. 2004;161:368-70.

35. Bebbington PE, Nayani T. The Psychosis Screening Questionnaire. Int J Methods Psychiatr Res. 1995;5:11-20.

36. Woods SW. Chlorpromazine equivalent doses for the newer atypical antipsychotics. J Clin Psychiatry. 2003;64:663-7.

37. Kay SR, Fiszbein A, Opler LA. The positive and negative syndrome scale (PANSS) for schizophrenia. Schizophr Bull. 1987;13:261-76.

38. Polari A, Lavoie S, Sarrasin P, Pellanda V, Cotton S, Conus P. Duration of untreated psychosis: a proposition regarding treatment definition. Early Inter Psychiatry. 2011;5:301-8.

39. Tonietto M, Rizzo G, Veronese M, Bertoldo A. Modelling arterial input functions in positron emission tomography dynamic studies. Conf Proc IEEE Eng Med Biol Soc. 2015;2015:2247-50. 
40. Tonietto M, Veronese M, Rizzo G, Zanotti-Fregonara P, Lohith TG, Fujita M, et al. Improved models for plasma radiometabolite correction and their impact on kinetic quantification in PET studies. J Cereb Blood Flow Metab. 2015;35(Sep):1462-9.

41. Tonietto M, Rizzo G, Veronese M, Borgan F, Bloomfield P, Howes $\mathrm{O}$, et al. A unified framework for plasma data modelling in dynamic Positron Emission Tomography studies. IEEE Trans Biomed Eng. 2018;66:1447-55.

42. McGinnity CJ, Riaño Barros DA, Rosso L, Veronese M, Rizzo G, Bertoldo A, et al. Test-retest reproducibility of quantitative binding measures of [11C]Ro15-4513, a PET ligand for GABAA receptors containing alpha5 subunits. Neuroimage 2017;152 (May):270-82.

43. Horder J, Andersson M, Mendez MA, et al. GABAA receptor availability is not altered in adults with autism spectrum disorder or in mouse models. Sci Transl Med. 2018;10:eaam8434.

44. Myers JF, Rosso L, Watson BJ, Wilson SJ, Kalk NJ, Clementi N, et al. Characterisation of the contribution of the GABAbenzodiazepine $\alpha 1$ receptor subtype to [(11)C]Ro15-4513 PET images. J Cereb Blood Flow Metab. 2012;32:731-44.

45. Logan J. Graphical analysis of PET data applied to reversible and irreversible tracers. Nucl Med Biol. 2000;27:661-70.

46. Salinas CA, Searle GE, Gunn RN. The simplified reference tissue model: model assumption violations and their impact on binding potential. J Cereb Blood Flow Metab. 2015;35:304-11.

47. Hammers A, Panagoda P, Heckemann RA, et al. [11C]Flumazenil PET in temporal lobe epilepsy: do we need an arterial input function or kinetic modeling? J Cerebr Blood Flow Metab. 2008;28:207-16.

48. Kang JI, Park HJ, Kim SJ, Kim KR, Lee SY, Lee E, et al. Reduced binding potential of GABA-A/benzodiazepine receptors in individuals at ultra-high risk for psychosis: an [18F]-fluoroflumazenil positron emission tomography study. Schizophr Bull. 2014;40:548-57.

49. Steiner J, Brisch R, Schiltz K, Dobrowolny H, Mawrin C, Krzyżanowska $\mathrm{M}$, et al. GABAergic system impairment in the hippocampus and superior temporal gyrus of patients with paranoid schizophrenia: a post-mortem study. Schizophr Res. 2016;177:10-7.

50. Zink M, Schmitt A, May B, Müller B, Demirakca T, Braus DF, et al. Differential effects of long-term treatment with clozapine or haloperidol on GABAA receptor binding and GAD67 expression. Schizophr Res. 2004;66:151-7.

51. Mick I, Ramos AC, Myers J, Stokes PR, Chandrasekera S, Erritzoe $\mathrm{D}$, et al. Evidence for GABA-A receptor dysregulation in gambling disorder: correlation with impulsivity. Addict Biol. 2017;22:1601-9.

52. Bymaster FP, Calligaro DO, Falcone JF, Marsh RD, Moore NA, Tye NC, et al. Radioreceptor binding profile of the atypical antipsychotic olanzapine. Neuropsychopharmacology. 1996;14:87-96.

53. Schotte A, Janssen PF, Gommeren W, Luyten WH, Van Gompel $\mathrm{P}$, Lesage AS, et al. Risperidone compared with new and reference antipsychotic drugs: in vitro and in vivo receptor binding. Psychopharmacology. 1996;124:57-73.

54. Schoemaker H, Claustre Y, Fage D, Rouquier L, Chergui K, Curet $\mathrm{O}$, et al. Neurochemical characteristics of amisulpride, an atypical dopamine D2/D3 receptor antagonist with both presynaptic and limbic selectivity. J Pharm Exp Ther. 1997;280:83-97.

55. Shapiro DA, Renock S, Arrington E, Chiodo LA, Liu LX, Sibley $\mathrm{DR}$, et al. Aripiprazole, a novel atypical antipsychotic drug with a unique and robust pharmacology. Neuropsychopharmacology. 2003;28:1400-11.

56. Adriano F, Caltagirone C, Spalletta G. Hippocampal volume reduction in first-episode and chronic schizophrenia: a review and meta-analysis. Neuroscientist. 2012;18:180-200.

57. Brugger SP, Howes OD. Heterogeneity and homogeneity of regional brain structure in schizophrenia: a meta-analysis. JAMA Psychiatry. 2017;74:1104-11.

58. Freund TF, Buzsáki G. Interneurons of the hippocampus. Hippocampus. 1996;6:347-470.

59. Heckers S, Konradi C. GABAergic mechanisms of hippocampal hyperactivity in schizophrenia. Schizophr Res. 2015;167:4-11.

60. Stefanits H, Milenkovic I, Mahr N, Pataraia E, Hainfellner JA, Kovacs GG, et al. GABAA receptor subunits in the human amygdala and hippocampus: immunohistochemical distribution of 7 subunits. J Comp Neurol. 2018;526:324-48.

61. Serwanski DR, Miralles CP, Christie SB, Mehta AK, Li X, De Blas AL. Synaptic and nonsynaptic localization of GABAA receptors containing the alpha5 subunit in the rat brain. J Comp Neurol. 2006;499:458-70.

62. Uhlhaas PJ, Singer W. Abnormal neural oscillations and synchrony in schizophrenia. Nat Rev Neurosci. 2010;11:100-13.

63. Farrant M, Nusser Z. Variations on an inhibitory theme: phasic and tonic activation of GABA(A) receptors. Nat Rev Neurosci. 2005;6:215-29.

64. Brickley SG, Mody I. Extrasynaptic GABA(A) receptors: their function in the CNS and implications for disease. Neuron. 2012;73:23-34.

65. Caraiscos VB, Elliott EM, You-Ten KE, Cheng VY, Belelli D, Newell JG, et al. Tonic inhibition in mouse hippocampal CA1 pyramidal neurons is mediated by alpha5 subunit-containing gamma-aminobutyric acid type A receptors. Proc Natl Acad Sci USA. 2004;101:3662-7.

66. Glykys J, Mann EO, Mody I. Which GABA(A) receptor subunits are necessary for tonic inhibition in the hippocampus? J Neurosci. 2008;28:1421-6.

67. Glykys J, Mody I. Hippocampal network hyperactivity after selective reduction of tonic inhibition in GABA A receptor alpha5 subunit-deficient mice. J Neurophysiol. 2006;95:2796-807.

68. Nakahara S, Matsumoto M, van Erp TGM. Hippocampal subregion abnormalities in schizophrenia: a systematic review of structural and physiological imaging studies. Neuropsychopharmacol Rep. 2018;38:156-66.

69. Talati P, Rane S, Kose S, Blackford JU, Gore J, Donahue MJ, et al. Increased hippocampal CA1 cerebral blood volume in schizophrenia. Neuroimage Clin. 2014;5:359-64.

70. Ongür D, Cullen TJ, Wolf DH, Rohan M, Barreira P, Zalesak M, et al. The neural basis of relational memory deficits in schizophrenia. Arch Gen Psychiatry. 2006;63:356-65.

71. Donegan JJ, Boley AM, Yamaguchi J, Toney GM, Lodge DJ. Modulation of extrasynaptic GABAA alpha 5 receptors in the ventral hippocampus normalizes physiological and behavioral deficits in a circuit specific manner. Nat Commun. 2019;10:2819.

72. Schulz JM, Knoflach F, Hernandez MC, Bischofberger J. Dendrite-targeting interneurons control synaptic NMDA-receptor activation via nonlinear $\alpha 5$-GABAA receptors. Nat Commun. 2018;9:3576. 